\title{
SABERES DOCENTES SOBRE O ESTUDANTE COM ALTAS HABILIDADES: estamos preparados para acolhê-lo?
}

\author{
KNOWING TEACHERS ABOUT THE STUDENT WITH HIGH SKILLS: ARE WE \\ PREPARED TO WELCOME HIM? \\ SABERES DOCENTES SOBRE EL ESTUDIANTE CON ALTAS HABILIDADES: \\ ¿ESTAMOS PREPARADOS PARA RECIBIRLO?
}

\author{
Hildegard Susana Jung* \\ iD http://orcid.org/oooo-0oo1-5871-306o \\ Douglas Vaz ${ }^{*}$ \\ (iD) http://orcid.org/oooo-OOO2-3950-0120 \\ Remi Maria Zanatta Benatti*** \\ (iD) $h$ ttp://orcid.org/oooo-0oo2-0366-8618
}

\author{
REVISTA PEDAGÓGICA \\ Revista do Programa de Pós-graduação em Educação da Unochapecó | ISSN 1984-1566 \\ Universidade Comunitária da Região de Chapecó | Chapecó-SC, Brasil \\ Como referenciar este artigo: JUNG, H. S.; VAZ, D.; BENATTI, R. M. Z. Saberes docentes sobre o estudante \\ com altas habilidades: estamos preparados para acolhê-lo?. Revista Pedagógica, Chapecó, v. 22, p. 1-16, 2020. \\ DOI: http://dx.doi.org/10.22196/rp.v22io.5061
}

\begin{abstract}
Resumo: O objetivo da pesquisa consiste em discutir sobre a perspectiva docente em relação à inclusão de alunos com altas habilidades no ambiente escolar. A metodologia é de abordagem qualitativa e buscou informações em uma revisão de literatura e em dados empíricos levantados por meio de um questionário enviado a docentes. Os resultados apontam para: a) a necessidade de uma cultura inclusiva na escola e na universidade; b) os professores não se sentem preparados para trabalhar com alunos com altas habilidades; c) a necessidade de uma sólida formação docente inicial e continuada que aborde as altas habilidades. Precisamos que a escola com a cultura de inclusão, na qual todos possam sentir-se acolhidos como parte importante do ambiente de aprendizagem. Os estudantes com altas habilidades são seres privilegiados com uma inteligência fora dos padrões para determinadas áreas e a escola pode ajudá-los a desenvolver este potencial para que tenham uma vida repleta de sentido e feliz.
\end{abstract}

Palavras-chave: Altas habilidades; Educação Básica; Inclusão escolar.

Resumen: El objetivo de la investigación consiste en discutir sobre la perspectiva docente con relación a la inclusión de alumnos con altas habilidades en el ambiente escolar. La metodología es de abordaje cualitativo y ha buscado informaciones en una revisión de literatura y en datos empíricos de un cuestionario enviado a docentes. Los resultados señalan a: a) la necesidad de una cultura inclusiva en la escuela y en la universidad; b) los profesores no se sienten preparados para trabajar con alumnos con altas habilidades; c) la necesidad de una sólida formación docente inicial y continuada que aborde las altas habilidades. Necesitamos una escuela con la cultura de inclusión, en la cual todos se puedan sentir amparados como parte importante del ambiente de aprendizaje. Los estudiantes con altas habilidades son seres privilegiados con una inteligencia fuera de los estándares para determinadas áreas y la escuela puede ayudarlos a desarrollar este potencial para que tengan una vida repleta de sentido y feliz.

Palabras-clave: Altas habilidades; Educación Básica; Inclusión escolar.

Abstract: The objective of the research is to discuss the teaching perspective regarding the inclusion of students with high skills in the school environment. The methodology is of qualitative approach and sought information in a literature review and empirical data collected through a questionnaire sent to teachers. The results point to: a) the need for an inclusive culture in school and university; b) teachers do not feel prepared to work with students with high skills; c) the need for solid initial and continuing teacher education that addresses high skills. We need the school with the culture of inclusion, in which everyone can feel welcomed as an important part of the learning environment. Students with high skills are privileged beings with non-standard intelligence in certain areas and the school can help them develop this potential so that they have a meaningful and happy life.

Keywords: High skills; Basic education; School inclusion. 


\section{Introdução}

A inclusão escolar é um tema relativamente recente. Autores como Gugel (2011), Santos e Paini (2013), Kortmann (2003), Sassaki (2003), entre outros averiguaram que, na antiguidade, as pessoas "diferentes" eram segregadas, por serem consideradas uma vergonha para a família. Assim, verdadeiras atrocidades eram cometidas, como o abandono, o isolamento ou a eliminação, como na Grécia Antiga, onde era costume atirar pessoas deficientes dos penhascos de uma cadeia de montanhas denominada Taygetos. Em Esparta, as crianças nascidas com algum tipo de deficiência eram lançadas ao mar e os pais tinham o pleno "direito" de sacrificar os filhos que não nasceram "normais" (GUGEL, 2011).

Apesar disso, Gugel (2011) relata que, em outros casos, como no Egito Antigo, as pessoas com deficiência exerciam suas funções normalmente. Os indivíduos com nanismo, inclusive, tinham tratamento especial, sendo empregados em altos postos públicos, com direito a funeral com honrarias.

Já outras civilizações amparavam as pessoas com deficiência, considerando que elas eram dignas de "pena", como mostra a pesquisa de Santos e Paini (2013). As autoras explicam que, em Atenas, influenciados por Aristóteles - que definiu a premissa jurídica até hoje aceita de que "tratar os desiguais de maneira igual constitui-se em injustiça" - os deficientes eram amparados e protegidos pela sociedade.

De acordo com Freitas, Fossatti e Kortmann (2017), por meio da Organização das Nações Unidas (ONU), 1981 foi escolhido como o "Ano Internacional das Pessoas Deficientes". A partir desse marco gerou-se maior mobilização pelo movimento de busca de direitos sociais. Neste ano, o termo "indivíduo" foi substituído pela palavra "pessoa" como o substantivo que deve acompanhar o adjetivo deficiente. Assim, podemos perceber a busca por igualar os direitos e tratamento com dignidade concedidos a todas as pessoas.

Segundo explica Sassaki (2003), a década de 1980 marca um período de maior visibilidade e esclarecimentos à sociedade em relação às pessoas deficientes. Nessa época, a Organização Mundial da Saúde (OMS) lança a classificação mundial de impedimentos, deficiências e incapacidades. Com isso, demonstra as características presentes nas pessoas com deficiência em cada uma dessas categorias.

Com relação à inclusão de pessoas com altas habilidades, não há muitas notícias sobre elas na antiguidade. Entretanto, de acordo com Santos e Paini (2013, p. 3), são conhecidos os casos de "Beethoven, Isaac Newton, Albert Einstein, John Kennedy, Walt Disney, Dr. Robert Jarvick, Thomas Edison, dentre outros". As autoras explicam que estas pessoas foram consideradas, quando estudantes, alunos com baixo rendimento. Ainda assim, todos tiveram grande destaque e contribuíram positivamente para a humanidade em várias áreas da ciência.
* Doutora em Educação pela Universidade La Salle. Professora e coordenadora do Curso de Pedagogia, pesquisadora e docente permanente do Programa de pós-graduação em Educação da Universidade La Salle. Vice líder do Grupo de Pesquisa Gestão Educacional nos Diferentes Contextos.

E-mail: hildegard.jung@unilasalle.edu.br.

** Doutorando e mestre em Educação pela Universidade La Salle. Professor e coordenador adjunto do Curso de Pedagogia, membro do Núcleo de Apoio Pedagógico e Líder do Programa Google For Education da Universidade La Salle. Integrante do Grupo de Pesquisa Gestão Educacional nos Diferentes Contextos. E-mail: douglas.vaz@unilasalle.edu.br.

**** Mestranda em Educação pela Universidade La Salle. Tutora na Graduação $\mathrm{EaD}$ do Curso de Pedagogia na Universidade La Salle.

E-mail: remi.benatti@unilasalle.edu.br. 
Como podemos perceber, apesar de todo o movimento em relação à inclusão, as ações inclusivas acabam voltando-se geralmente à pessoa com deficiência e não à pessoa com altas habilidades. No ambiente escolar, não raramente, as duas coisas se confundem e acabam sendo generalizadas como deficiências (FLEITH, 2007; FLEITH e ALENCAR, 2009; ALENCAR, 2007a).

Neste sentido versa o problema desta pesquisa: qual é a perspectiva docente em relação à inclusão de alunos com altas habilidades no ambiente escolar? Assim, o estudo tem como objetivo discutir a perspectiva docente em relação à inclusão de alunos com altas habilidades no ambiente escolar. Utilizamos o termo altas habilidades, neste estudo, como sinônimo de superdotação, mas optamos pelo primeiro.

O estudo é de abordagem qualitativa, o qual busca seus dados de análise na revisão de literatura acerca da temática e se ampara, empiricamente, nas respostas a um questionário enviado às acadêmicas do curso de Pedagogia de uma universidade comunitária da região metropolitana de Porto Alegre, Rio Grande do Sul. Para o exame dos dados utilizamos a técnica de Análise de Conteúdo (BARDIN, 2006).

Com relação à arquitetura do presente artigo, após esta introdução, apresentamos o percurso metodológico, seguido do referencial teórico que embasou as discussões. Na sequência, figura a análise e discussão dos dados e, por último, trazemos as considerações finais e referências.

\section{Metodologia}

A metodologia da pesquisa tem cunho qualitativo e segue as orientações de Bardin (2006) e Gil (2008). De acordo com estes autores, a pesquisa qualitativa não faz uso de análises estatísticas e, por isso, não lança mão de cálculos matemáticos para a análise de seus dados. Ainda que este estudo apresente alguns gráficos relacionados com os dados levantados, Bardin (2006) argumenta que a pesquisa qualitativa não rejeita dados quantitativos, quando for o caso. Ao contrário, segundo a autora, eles tornam a pesquisa qualitativa mais robusta.

Com relação à coleta de dados, estes foram levantados em uma revisão bibliográfica acerca do tema, realizada em artigos científicos disponíveis em plataformas como Scielo e Capes Periódicos, bem como em livros sobre a temática, além de documentos legais. Os dados empíricos foram coletados por meio de um questionário enviado aos acadêmicos (que já atuam na docência) do Curso de Pedagogia de uma universidade comunitária da região metropolitana de Porto Alegre, RS.

De acordo com Gil (2008, p. 121), o questionário pode ser definido como uma técnica composta por um conjunto de questões enviadas aos sujeitos da pesquisa "com o propósito de obter informações sobre conhecimentos, 
crenças, sentimentos, valores, interesses, expectativas, aspirações, temores, comportamento presente ou passado". Dessa maneira, o referido questionário ${ }^{1}$ contém seis questões, sendo as primeiras duas destinadas a construir um perfil dos participantes: 1) Qual a sua idade?; 2) Qual o seu tempo de exercício no magistério?; 3) Que características você atribui a um(a) aluno(a) com altas habilidades?; 4) Você se considera preparado(a) para trabalhar com alunos com altas habilidades?2; 5) Na sua opinião, como o tema das altas habilidades deve ser abordado pela escola? Por quê?; 6) Como seria, na sua opinião, a formação ideal para trabalhar com alunos com altas habilidades?

O critério de inclusão dos participantes na pesquisa foi ser estudante do Curso de Pedagogia da referida universidade, já em exercício no Magistério e o aceite em participar da pesquisa. Com relação aos critérios éticos, por se tratar de um questionário elaborado no recurso Google Forms, este, por si só já garante o anonimato dos respondentes, posto que não registra o endereço eletrônico de quem responde. Na página de abertura do questionário colocamos os dados da pesquisa, da pesquisadora, bem como o Termo de Consentimento Livre e Esclarecido (TCLE), de maneira que, ao optar pela participação, o(a) respondente precisou clicar em "continuar para a próxima seção". Além disso, ao concluir as respostas, os participantes consentiram ao clicar em "enviar" e somente assim as suas respostas foram contabilizadas.

Ainda com relação aos aspectos éticos, os participantes foram nomeados pela letra "D", de "docentes" e receberam, aleatoriamente, a numeração sequencial de o a 20 (número de respostas) para que pudéssemos nos referir aos depoimentos no momento da análise e discussão dos dados.

A análise de conteúdo se baseará nas orientações de Bardin (2006, p. 95), a qual recomenda que sejam seguidas três fases de organização da pesquisa: “(a) pré-análise; (b) exploração do material; e (c) tratamento dos dados, inferência e interpretação". Exploramos o material realizando leitura de artigos e capítulos. Na fase de tratamento e inferências, recebendo as respostas dos questionários, fizemos a interpretação. Este trabalho é definido por Bardin (2006, p. 37) como a busca de elementos em comum, que são uma "espécie de gavetas ou rubricas, significativas que permitem a classificação dos elementos de significação constitutivos da mensagem".

A respostas foram analisadas à luz da teoria, de onde emergiram as inferências das autoras. No tópico análise e discussão dos dados foram registrados esses elementos da pesquisa.

\section{Referencial teórico}

Para melhor entendimento do objeto de pesquisa, dividimos o referencial teórico de forma a trazer uma visão
1 Disponível em: https://docs.google.com/forms/d/e/1FAIpQLSet- 8 e w F Q v 48 Ji 9 yt E U 1 A M O PvKwwL59K_zfkGUqq26Aw2ibbw/ viewform?usp=sf_link.

2 Esta questão segue o esquema de uma escala Likert: Muito preparado; Medianamente preparado; Pouco preparado; Nada preparado. 
longitudinal sobre a inclusão até chegarmos à atual conjuntura dessa questão.

\subsection{A inclusão através dos tempos}

De acordo com Santos e Paini (2013), dentre os poetas gregos o mais famoso é Homero que, pelos relatos, era cego e teria vivido em época anterior a VII a.C. Entretanto, em Esparta e em Roma, as leis não eram favoráveis às pessoas com algum tipo de deficiência. De acordo com as autoras, naquela época, as crianças nascidas com deformidades físicas eram geralmente afogadas. Entretanto, muitos pais não tinham coragem de fazê-lo e acabavam abandonando seus filhos em cestos no Rio Tibre ou em outros lugares sagrados. A prática era bastante comum, como conta a história bíblica do profeta Moisés, abandonado em um cesto no Rio Nilo.

Os sobreviventes desses abandonos eram comumente explorados nas cidades por "esmoladores", ou então passavam a fazer parte de circos para o entretenimento dos mais ricos. O filme histórico-biográfico O homem elefante ${ }^{3}$ lançado em 1980 pelo diretor David Lynch, baseia-se na história real de Joseph Merrick, um homem que viveu em Londres no final do século XIX, o qual teve 90\% do seu corpo deformado devido a uma enfermidade. No drama, Joseph é exibido em um circo de aberrações por um animador alcoólico e sádico. Sua cabeça é mantida encapuzada por seu "dono", que o vê como deficiente intelectual.

Kortmann (2003) explica que uma linguagem para as pessoas surdas começou a ser desenvolvida na Itália já nos anos de 1500 pelo médico e matemático Gerolamo Cardomo (1501 a 1576). Este influenciou o monge beneditino Pedro Ponce de Leon (1520-1584) a desenvolver um método de sinais para educar as pessoas com deficiência auditiva, contrariando o pensamento da sociedade da época que não acreditava que pessoas surdas pudessem ser educadas. Os estudos provocaram experiências e novas pesquisas por todo o mundo. Assim, na Espanha, em 1620, no seu livro Reduction de las letras y arte para ensenar a hablar los mudos, Pablo Bonet demonstra pela primeira vez o alfabeto na língua de sinais.

De acordo com Gugel (2011), vários gênios da história tinham deficiências, como por exemplo Luís de Camões (1524 a 1580), o poeta de Os Lusíadas, o qual perdeu a visão de um dos olhos em uma batalha. John Milton (1608-1674), um dos maiores poetas ingleses, era cego. Galileo Galilei, físico, matemático e astrônomo, em consequência de seu reumatismo, ficou cego nos últimos anos de sua vida, assim como astrônomo alemão Johannes Kepler (1571 a 1630), que tinha deficiência visual e desenvolveu estudos sobre o movimento dos planetas. A autora explica ainda que, na China, já no século VI havia nobres que usavam cadeiras de rodas. Na Alemanha, Stephen Farfler, paraplégico, construiu, em 1655, uma cadeira de rodas para se locomover,
3 No original, em inglês, The Elephant Man. 
composta por duas rodas atrás e uma na frente, acionada por duas manivelas giratórias.

Sassaki (2003) explica que durante os séculos XVII e XVIII, principalmente devido ao grande número de mutilados nas guerras, houve significativo desenvolvimento no atendimento às pessoas com deficiência em hospitais. Havia assistência especializada em ortopedia para os mutilados das guerras e para pessoas cegas e surdas. O médico francês Philippe Pinel (1745-1826), considerado o pai da psiquiatria, passou a ensinar que pessoas com perturbações mentais devem ser tratadas como doentes, ao contrário do que acontecia na época, quando eram tratados com violência e discriminação.

Mais recentemente, a Declaração de Incheon (UNESCO, 2015), de maio de 2015, mobilizou todos os países e parceiros em torno da educação e suas metas, além de propor formas de implementar, coordenar, financiar e monitorar a Educação 2030 para garantir oportunidades de educação de qualidade inclusiva e equitativa, assim como de aprendizagem ao longo da vida para todos. Neste encontro foi firmado o Marco de Ação rumo a uma educação de qualidade inclusiva e equitativa e à educação ao longo da vida para todos (UNESCO, 2015). A partir deste marco, outras ações inclusivas se traduziram na prática nos âmbitos nacional, regional e global. No Brasil, por exemplo, um dos reflexos foi a Lei 13.409/16, a qual estendeu o benefício das cotas, que já abrangia negros, pardos e indígenas, também às pessoas com deficiência.

\subsection{Altas habilidades: compreendendo a situação}

No Brasil, as Diretrizes Gerais para o Atendimento aos alunos de Altas Habilidades/Superdotação e Talentos propõem a seguinte definição:

As altas habilidades referem-se aos comportamentos observados e/ou relatados que confirmem a expressão de traços consistentemente superiores em relação a uma média (por exemplo: idade, produção ou série escolar) em qualquer campo do saber ou do fazer. Deve-se entender por traços as formas consistentes, ou seja, aquelas que permanecem com frequência e duração no repertório dos comportamentos da pessoa, de forma a poderem ser registradas em épocas diferentes e situações semelhantes (BRASIL, 1995, p. 13).

De acordo com a Secretaria de Educação Especial do Ministério da Educação (MEC, 2016) de forma geral as altas habilidades caracterizam pelo alto potencial de aptidões, talentos e habilidades. Estas características podem ser evidenciadas por alta performance em diversas áreas de atividade do estudante. Entretanto, é necessário constatar que tais aptidões sejam constantes. 
Dessa maneira, em muitos casos é registrada a precocidade do aparecimento das habilidades e a resistência dos indivíduos aos obstáculos e frustrações existentes no seu desenvolvimento. De acordo com Negrini e Freitas (2008), por muito tempo a inteligência foi relacionada aos resultados dos testes de Quociente de Inteligência (QI). Segundo explicam,

Estes testes possuem tabelas numéricas de reconhecimento da inteligência, porém são capazes de medir somente as inteligências lógico-matemática, linguística e espacial. Os testes de "QI" vêm sofrendo críticas, tendo em vista que são aplicados isoladamente, sem levar em consideração a realidade do aluno, nem mesmo levam em consideração as demais capacidades humanas (NEGRINI; FREITAS, 2008, p. 275).

A pessoa com altas habilidades, portanto, não necessariamente precisa ter um resultado numérico elevado nos testes de QI. Segundo os autores, "para apresentar altas habilidades, deve apresentar as características contidas nos Três Anéis (Envolvimento com a tarefa, Capacidade Superior e Criatividade)" (NEGRINI e FREITAS, 2008, p. 277). Além disso, esclarecem que somente a interlocução entre os três anéis, em determinada área do conhecimento, caracteriza uma pessoa com esta habilidade. No mesmo sentido está o entendimento de Winner (1998, p. 247-248), quando o autor esclarece que

As crianças superdotadas não são apenas mais rápidas do que as crianças normais, mas são também diferentes. Porque requerem apoio estruturado mínimo, porque fazem descobertas sozinhas e inventam novas formas de entender e porque têm tamanha fúria por dominar, elas são diferentes das crianças que apenas trabalharam com afinco extremo.

Como podemos perceber, este autor também não acredita em testes de QI. A identificação de alunos com altas habilidades envolve ter conhecimento profundo das características individuais que evidenciam no estudante uma capacidade superior, a qual poderá ser em uma área específica de interesse. É necessário, entretanto, tomar cuidado para não rotular esses estudantes. Trata-se, portanto, de uma identificação que deverá ser realizada por uma equipe multidisciplinar e realizada por meio de "inúmeros instrumentos que permitam uma visão integral do sujeito" (NEGRINI; FREITAS, 2008, p. 279).

Além da questão apontada sobre o "rótulo", Alencar (2007b), afirma que as crianças com altas habilidades podem apresentar dificuldades em interagir socialmente, ou não. De acordo com a autora, enquanto algumas pesquisas 
apontam para um lado, outras apontam para outro: "enquanto há autores que defendem a ideia de que os alunos superdotados apresentam uma predisposição a dificuldades sócio-emocionais, outros apontam a direção contrária, ressaltando a inexistência de evidência de maior grau de dificuldades sócio-emocionais" (ALENCAR, 2007b, p. 373). Dessa forma, a autora lembra que poderá haver um descompasso entre o desenvolvimento intelectual (mais rápido) e o desenvolvimento físico-social. Por fim, a autora conclui que, quando a criança é extremamente inteligente, tende a ser menos sociável, vindo a concordar com Gross (1993, p. 497), quando esta explica que

Estudantes excepcionalmente inteligentes diferem de forma radical de outros moderadamente superdotados não apenas em seu desenvolvimento cognitivo, mas em seu crescimento afetivo, desenvolvimento moral, interesses recreativos, interesses de leitura, escolha de amizades, atitudes e valores, além da maneira como veem o mundo.

Como vimos, trata-se de um estudante que não somente interage de forma distinta no âmbito social, mas que vê o mundo sob um prisma distinto.

\subsection{Docência e altas habilidades}

A partir da Lei de Diretrizes e Bases da Educação Nacional ((LDB), de 20 de dezembro de 1996, temos a proposta de uma educação inclusiva. Entretanto, para o docente nem sempre é fácil a tarefa de conviver, identificar ou auxiliar um estudante com altas habilidades, posto que sua formação pode não ter lhe oferecido conhecimentos suficientes a respeito da temática (MARTINS, 2010).

Além disso, como alertam Rech e Freitas (2005, p. 5), geralmente "o professor tem de dar conta de uma sala superlotada de alunos, cada um com suas particularidades". Segundo as autoras, é comum que, neste cenário, os conteúdos sejam desenvolvidos com a maioria, mas provavelmente haverá uma minoria que não será atendida.

Neste contexto, Azevedo e Mettrau (2010) realizaram um estudo empírico no qual concluíram que os professores necessitam de maiores esclarecimentos sobre o tema das altas habilidades. Além disso, "demonstram medo, receio, exatamente pela insegurança trazida pelo pouco saber que acreditam ter (AZEVEDO; MATTRAU, 2010, p. 41). Outro ponto assinalado pelas autoras consiste no mito das altas habilidades, o qual atrapalha a observação e faz com que os docentes acreditem "que superdotados têm alto desempenho escolar em todas as disciplinas acadêmicas. Os profissionais da escola que creem nesse mito não admitem a hipótese de um possível insucesso, e criam a perspectiva de que tudo seja fácil para esse aluno" (AZEVEDO; MATTRAU, 2010, p. 41). 
Por outro lado, Mattei (2008) observou que os estudantes questionadores muitas vezes não são bem vistos pelos professores, de forma que podem acabar sendo ignorados ou rotulados como indisciplinados. De acordo com a autora, estes educandos, uma vez ignorados ou rotulados, podem acabar frustrados e, inclusive, evadindo dos estudos, como ela mesma explica:

Os alunos portadores de altas habilidades, assim como outros educandos, acabam frustrando-se com o ensino e buscam outras alternativas muitas vezes inconvenientes ao professor (perturbando as aulas, a "indisciplina”), enquanto outros acabam evadindo da escola [...]. O aluno com altas habilidades almeja mais do ensino. Ele busca conhecimentos que possam ser úteis a sua vida. É questionador e tem grande facilidade para o aprendizado, o que pode algumas vezes perturbar o professor, por este não estar seguro em atender estes alunos especiais (MATTEI, 2008, p. 80).

Martins (2010) assegura que seria necessária uma formação mais sólida dos profissionais da educação para o trabalho com estudantes com altas habilidades. A autora acredita que estudos somente teóricos, como frequentemente vemos nos cursos de graduação, não dão conta da necessidade atual. É necessário, segundo ela, que haja formação inicial e continuada nesta área que contemple a articulação entre a teoria e a prática, envolvendo "conceitos de altas habilidades/superdotação, estratégias de identificação, comportamentos típicos dos alunos e orientações pedagógicas relacionadas às atuações práticas" (MARTINS, 2010, p. 59).

\section{Análise e discussão dos dados}

Este tópico está destinado à análise e discussão dos resultados, no qual serão examinados os dados coletados à luz da teoria.

\subsection{Caracterização dos sujeitos da pesquisa}

Os sujeitos da pesquisa, como já anunciado, consistiram em 20 estudantes do Curso de Pedagogia de uma universidade comunitária da região metropolitana de Porto Alegre, os quais já atuam na docência. Trata-se, portanto, de um público predominantemente jovem, o que a pesquisa confirmou, mostrando que as idades variam, em sua maioria, dos 20 aos 40 anos (65\% das respostas). A figura 01 apresenta o gráfico com as proporções das idades, como segue. 


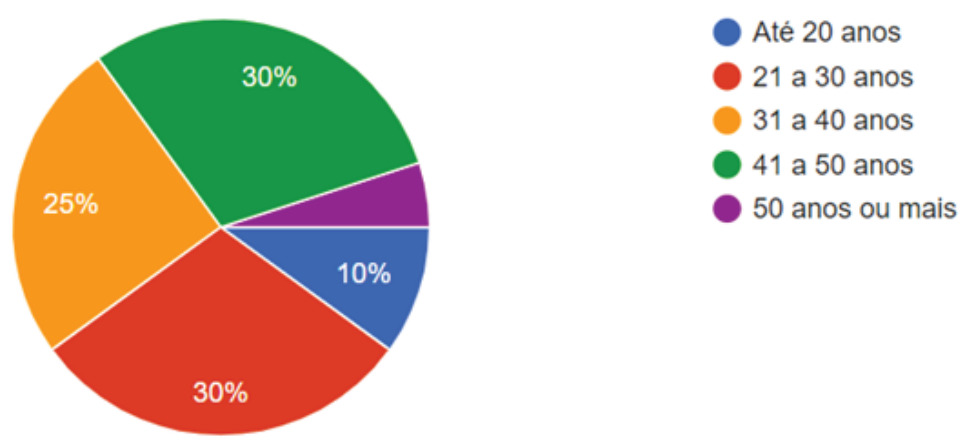

Figura 1. Idade dos participantes da pesquisa. Fonte: Dados da pesquisa, 2019.

Como vimos, $10 \%$ dos respondentes têm até 20 anos; $30 \%$ possuem de 31 a 30 anos, enquanto que $25 \%$ estão na faixa dos 31 a 40 anos, o que totaliza um público bastante jovem em sua maioria, como afirmamos. A faixa etária de 41 a 50 anos é de $30 \%$ e, com mais de 50 anos somente participou um respondente (5\%).

Com relação ao tempo de experiência no magistério, este foi bastante diverso, sendo que um participante tem seis meses de experiência e o mais experiente exerce a profissão a 27 anos. A média entre os respondentes é de dois anos de magistério.

\subsection{A percepção docente sobre os estudantes com} altas habilidades: características

Quando perguntados sobre as características que atribuem a um estudante com altas habilidades, os participantes da pesquisa foram bastante heterogêneos em suas respostas: enquanto alguns consideram esse estudante cooperativo, outros o consideram agressivo, como podemos perceber nas respostas de D5: "Precocidade, insistência em fazer as coisas a seu modo, comprometimento com a tarefa"; e D9: "É uma criança com uma inteligência altíssima, mas às vezes se tornam agressivos".

Entretanto, 25\% das respostas esteve de acordo com o que vimos em Negrini e Freitas (2008), ou seja, os estudantes com altas habilidades não necessariamente precisam ser excelentes em todas as disciplinas, como apontou D11: "Um aluno que pode apresentar maior habilidades em uma determinada área e em outras pode demonstrar dificuldade". Como vemos, somente um quatro dos respondentes tem uma visão realista sobre as características dos estudantes com altas habilidades.

Por outro lado, $40 \%$ dos respondentes mencionaram que as crianças com altas habilidade têm dificuldades de interagir socialmente, como vimos com Alencar (2007b) e Gross (1993). Embora tenhamos que concordar com as autoras citadas, parece-nos que os participantes, neste ponto, apresentam maior conhecimento a respeito do tema, ainda que se trate de menos que a metade dos respondentes. 
O depoimento de D12 foi bastante lúcido: "O aluno pode também ter dificuldades no âmbito social, com uma postura mais individual, com pouca comunicação, o que não significa que ele não interaja, somente a interação é ao seu tempo e a sua maneira".

\subsection{O despreparo docente para o trabalho com estudantes de altas habilidades}

As respostas à pergunta "Você se considera preparado(a) para trabalhar com alunos com altas habilidades/superdotação?” trouxeram uma preocupante realidade com relação ao preparo docente para o trabalho com estudantes de altas habilidades em nossas escolas. Aos serem submetidos a esse questionamento, nenhum respondente marcou a opção "Muito preparado". Entre as respostas, tivemos 50\% afirmando que se sentem "Pouco preparados"; 30\% alegam que estão "Medianamente preparados"; e 20\% responderam que se sentem "Nada preparados" para trabalhar com estudantes com altas habilidades.

Se somarmos as respostas que vão desde "Medianamente" a "Pouco preparado", temos a totalidade, ou seja, $100 \%$ dos respondentes não se sentem suficientemente preparados para o trabalho com estes estudantes, como averiguamos na literatura que constitui o referencial teórico da pesquisa. A Figura 02 apresenta o gráfico contendo esses os dados:
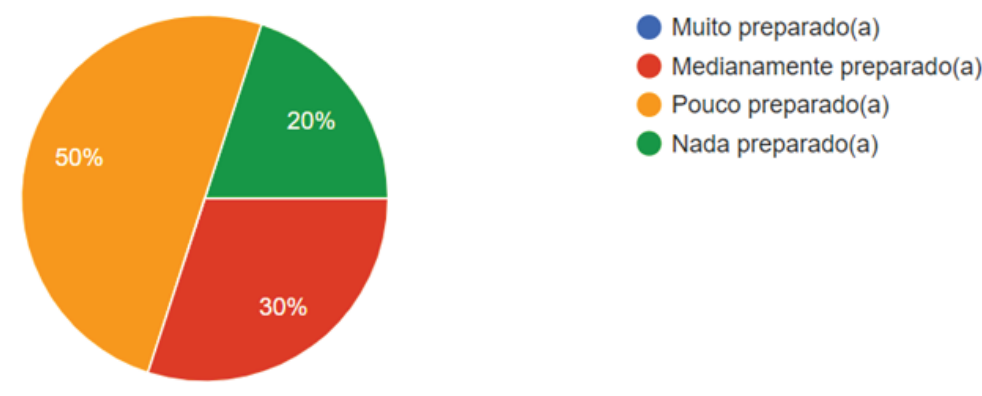

Figura 2. Você se sente preparado(a) para trabalhar com alunos com altas habilidades? Fonte: Dados da pesquisa, 2019.

O cenário retrata o que afirmam Martins (2010), Rech e Freitas (2005), e outros autores que advogam por uma formação mais sólida para os docentes no sentido não somente de identificar altas habilidades, mas também de saber que práticas pedagógicas são mais adequadas para que estes estudantes tenham êxito em sua vida escolar.

\subsection{A escola: lugar de inclusão}

Quando perguntados sobre como o tema altas habilidades poderia ser abordado na escola, $45 \%$ dos respondentes mencionaram a inclusão. Ou seja, na opinião dos 
participantes a escola é um lugar de inclusão, no qual o tema deve ser abordado com naturalidade, como ponderou D9: "Deve ser muito mais abordado nas escolas! Pois eu vejo que as escolas não falam sobre alunos com essas habilidades, precisam de atenção, muito cuidado e carinho".

À luz da teoria, principalmente em consonância com Freitas, Fossatti e Kortmann (2017) e Kortmann (2013), temos uma vasta legislação no âmbito da inclusão, seja em nível nacional ou internacional, mas de fato nos falta uma cultura da inclusão. Segundo os autores, há uma importante distinção entre incluir e integrar. Ou seja, não basta simplesmente integrar os estudantes com altas habilidades nas salas de aulas.

É necessário que todos os estudantes se sintam incluídos verdadeiramente em todas as atividades da escola, nas práticas do cotidiano da sala de aula, como afirma D10 em seu depoimento: "para realmente oferecer a esses alunos um atendimento eficiente, pois geralmente as escolas não conseguem realizar uma inclusão real de alunos com essas habilidades".

\subsection{Uma proposta de formação docente}

A última pergunta do questionário versou em torno de uma proposta de formação docente: "Como seria, na sua opinião, a formação ideal para trabalhar com alunos com altas habilidades?”. Apesar de significativamente diversas, as respostas enfocaram três eixos principais: a) formação permanente, com participação em especializações e cursos; b) a compreensão das altas habilidades por meio de estudos direcionados ao tema; c) educação humana e inclusiva.

Com relação ao primeiro tema, percebemos que os próprios profissionais estão muito cientes da necessidade de formação permanente, estando sempre atualizados, por meio da pesquisa e de cursos, e especializações, como vimos com Martins (2010). Esta autora defende uma formação sólida, tanto inicial como continuada. Percebemos, ainda, que os professores se ressentem de uma abordagem mais direcionada ao tema altas habilidades. Em termos de políticas públicas percebemos, portanto, que ainda há um longo caminho a ser percorrido. Por fim, os respondentes apontaram a necessidade de uma proposta educacional que leve em conta o ser humano em sua integralidade, ou seja, não podemos somente encarar os estudantes sob o âmbito intelectual, mas como um ser humano dotado de sentimentos, de fraquezas, de vivências anteriores boas e ruins, e que precisa, como explica Gross (1993), ser visto e sentido com e por todos os sentidos. Acreditamos que a declaração de D18 representa de forma bastante completa esse pensamento:

Acredito que a principal formação deve ser humana. O docente precisa estar aberto a novas características dos seus alunos e 
alunas, desenvolvendo paciência e flexibilidade ao trabalhar com os discentes, independente de laudo ou não. Após essa primeira "formação" é de suma importância que os docentes procurem sempre estar em formação, seja na área de inclusão como em diversas temáticas. Visando comprometimento com a educação e com a pesquisa, tornando-se um professor pesquisador.

Como vimos, para que a educação seja inclusiva de fato, não pode somente prescindir de uma legislação que a aborde. Este é apenas o começo. Trata-se, como apontam Freitas, Fossatti e Kortmann (2017), de desenvolvermos uma cultura inclusiva na escola e na universidade.

\section{Considerações finais}

A pesquisa buscou suscitar o debate em torno da perspectiva docente em relação à inclusão de alunos com altas habilidades no ambiente escolar. Como vimos, apesar de não se sentirem preparados para o trabalho com estes estudantes, os professores acreditam que a formação, seja inicial e/ou continuada, poderá capacitá-los para uma melhor compreensão, identificação e escolha de práticas pedagógicas mais adequadas para este público.

Outro dado importante apontado pela pesquisa diz respeito à visão dos professores com relação à escola como um espaço de inclusão, no qual precisa existir uma cultura inclusiva, que transcende a legislação e se preocupa verdadeiramente com o ser humano que ali está e que traz dificuldades, facilidades, vivências anteriores, medos e alegrias. Precisamos, portanto, que a escola tenha uma cultura de inclusão, na qual todos possam sentir-se acolhidos como uma parte importante do ambiente de aprendizagem.

Os estudantes com altas habilidades são seres privilegiados com uma inteligência fora dos padrões para determinadas áreas e podemos ajudá-los a desenvolver este potencial para que tenham uma vida repleta de sentido, uma vida feliz. Finalmente, acreditamos que a presente pesquisa, ao trazer à luz a discussão sobre os estudantes com altas habilidades, poderá suscitar novos questionamentos e mais estudos empíricos, talvez abordando a perspectiva discente. $\mathrm{O}$ debate está aberto.

\section{Referências}

ALENCAR, Eunice M. L. S. Indivíduos com altas habilidades/superdotação: clarificando conceitos, desfazendo ideias errôneas. A construção de práticas educacionais para alunos com altas habilidades/superdotação, v. 1, p. 16-23, 2007 a. 
ALENCAR, Eunice M.L.S. Características sócio-emocionais do superdotado: questões atuais. Psicologia em estudo, v. 12, n. 2, p. 371-378, 2007b.

AZEVEDO, Sonia Maria Lourenço de; METTRAU, Marsyl Bulkool. Altas habilidades / superdotação: mitos e dilemas docentes na indicação para o atendimento. Psicologia: ciência e profissão, v. 30, n. 1, p. 32-45, 2010.

BARDIN, Laurence. Análise de Conteúdo. Lisboa: Edições 70, 2006.

BRASIL. Lei n. 13.409, de 28 de dezembro de 2016. Altera a Lei $\mathrm{n}^{0} 12.711$, de 29 de agosto de 2012, para dispor sobre a reserva de vagas para pessoas com deficiência nos cursos técnico de nível médio e superior das instituições federais de ensino. Brasília, DF, 2016. Disponível em: http:// www.planalto.gov.br/ccivil_03/_Ato2015-2018/2016/ Lei/L13409.htm. Acesso em: 21 jun. 2019.

BRASIL. Lei n. 13.146, de 6 de julho de 2015. Institui a Lei Brasileira de Inclusão da Pessoa com Deficiência (Estatuto da Pessoa com Deficiência). Brasília, 2015. Disponível em: http://www.planalto.gov.br/ccivil_03/_Ato20152018/2015/Lei/L13146.htm. Acesso em: 21 jun. 2019.

BRASIL. Lei n. 9394, de 20 de dezembro de 1996. Estabelece as diretrizes e bases da educação nacional. Brasília, 1996. Disponível em: http://www.planalto.gov.br/ ccivil_03/leis/l9394.htm. Acesso em: 21 jun. 2019.

BRASIL. Secretaria de Educação Especial. Política Nacional de Educação Especial. Ministério da Educação e do Desporto, Secretaria de Educação Especial, 1995.

FLEITH, Denise de Souza. A construção de práticas educacionais para alunos com altas habilidades/ superdotação. Brasília: Ministério da Educação, Secretaria de Educação Especial, 2007.

FLEITH, Denise Souza; ALENCAR, Eunice M. L Soriano. Desenvolvimento de talentos e altas habilidades: orientação a pais e professores. Porto Alegre: Artmed Editora, 2009.

FREITAS, Simone Van Der Halen; FOSSATTI, Paulo; KORTMANN, Gilca Maria Lucena. Inclusão de pessoas com deficiência (PCD) na educação superior: um olhar a partir das políticas de inclusão. In: GIANEZINI, Kelly; GROSS, Jacson. (Orgs.). Estudos contemporâneos em ciências jurídicas e sociais. Criciúma, SC: Unesc, 2017.

FREITAS, Soraia N.; PÉREZ, S. G. P. B. Altas habilidades/superdotação: atendimento especializado. Marília: Abpee, 2012. 
GIL, Antônio Carlos. Como elaborar projetos de pesquisa. São Paulo: Atlas, 2008.

GROSS, M. U. M. Nurturing the talents of exceptionally gifted individuals. In: K. A. Heller; F. J. Mönks; A. H. Passow (Orgs.). International handbook of research and development of giftedness and talent (p. 473-490). England: Oxford Pergamos, 1993.

GUGEL, Maria Aparecida. A pessoa com deficiência e sua relação com a história da humanidade. Florianópolis, 2011. Disponível em: $<$ http://www. ampid. org. br/Artigos/PD_Historia. php> Acesso em: 09 nov. 2018.

KORTMANN, Gilca Maria Lucena. A inclusão da criança especial começa na família. Educação Especial: em direção à Educação Inclusiva, v. 3, p. 221-235, 2003.

MARTINS, Alexandra da Costa Souza et al. Características desejáveis em professores de alunos com altas habilidades/superdotação. Dissertação (Mestrado em Educação). 62f. Brasília, Universidade Católica de Brasília. 2010.

MATTEI, Giovana. O professor e aluno com altas habilidades e superdotação: relações de saber e poder que permeiam o ensino. Revista Educação Especial, v. 21, n. 31, 2008.

MEC. Secretaria da Educação Especial. Saberes e práticas da inclusão, 2016. Disponível em: http://portal.mec. gov.br/seesp/arquivos/pdf/altashabilidades.pdf. Acesso em 09 dez. 2018.

NEGRINI, Tatiane; FREITAS, Soraia Napoleão. A identificação e a inclusão de alunos com características de altas habilidades/superdotação: discussões pertinentes. Revista Educação Especial, v. 21, n. 32, p. 273-284, 2008.

SANTOS, Elizabete Aparecida da Silva; PAINI, Leonor Dias. Conhecendo o aluno com altas habilidades/superdotação. In: Cadernos PDE - Os desafios da escola pública paranaense na perspectiva do professor PDE. Curitiba, 2013. Disponível em; https://goo.gl/b5i2G4. Acesso em 21 jun. 2019.

SASSAKI, Romeu Kazumi. Como chamar as pessoas que têm deficiência. Revista da Sociedade Brasileira de Ostomizados, v. 1, n. 1, p. 8-11, 2003.

PÉREZ, S. G. P. B. Mitos e crenças sobre as pessoas com altas habilidades: alguns aspectos que dificultam o seu atendimento. Cadernos de Educação Especial, v. 2, n. 22, p. 45-59, 2003. 
RECH, Andréia Jaqueline Devalle; FREITAS, Soraia Napoleão. O papel do professor junto ao aluno com Altas Habilidades. Revista Educação Especial, p. 59-71, 2005.

UNESCO. Educação 2030: Declaração de Incheon e Marco de Ação; rumo a uma educação de qualidade inclusiva e equitativa e à educação ao longo da vida para todos. World Education Forum, Incheon, Korea R, 2015. Disponível em: https://unesdoc.unesco.org/ark:/48223/pfoooo243278_ por. Acesso em 21 jun. 2019.

WINNER, Ellen. Crianças superdotadas: mitos e realidades. Tradução Sandra Costa. Porto Alegre: Artes Médicas, 1998.

Recebido em: 18/o8/2019 Aprovado em: 07/03/2020 Publicado em: 01/04/2020 